\title{
Intercellular Transport Process
}

National Cancer Institute

\section{Source}

National Cancer Institute. Intercellular Transport Process. NCI Thesaurus. Code C40801.

Any cellular process involved in translocation of substances into or out of a cell. 